ALPHA Nº 27 Diciembre 2008 (147-166)

ISSN 0716-4254

http://alpha.ulagos.cl

\title{
IDEAS POLÍTICAS Y RETÓRICAS DEL PRESIDENCIALISMO CONSTITUYENTE EN ESTADOS UNIDOS
}

Political and rhetorical ideas of the constituent presidentialism in the USA

José J. Sanmartín*

Resumen

En este artículo se exploran las ideas políticas y retóricas que sedimentaron la ideología norteamericana en su etapa constituyente como un conjunto ideológico plural e irregular, a un mismo tiempo. La influencia del universo nacionalista que conformaron los Founding Fathers de los Estados Unidos dejó su impronta en la Presidencia como institución simbólica que encarna desde entonces un empirismo -mayormente maquiavélico, aunque nunca reconocido- atemperado por un idealismo formal, pero sólo parcialmente efectivo. Esa tradición cultural - y sus contradicciones - llega hasta nuestro tiempo, donde un Presidente como Clinton pudo recuperar la vieja bandera del American Dream, actualizándolo, con el objeto de consolidar un nuevo liberalismo social.

Palabras clave: Estados Unidos. Primer constitucionalismo. Presidente. Retórica política. Clinton.

\begin{abstract}
In this article we will examine both political and rhetorical ideas as an ideological plural and irregular set that —at the same time - cemented United States ideology in its early stage. The influence of this nationalist universe promoted by the Founding Fathers shaped the Presidency as a symbolic institution that has embodied, since then, an empiricism - mostly Machiavellian, though never recognizedmoderated by a formal idealism, but only partially effective. This cultural tradition - and its contradictions - come up to the present time, where a President such as Clinton could recover the old flag of the American Dream, updating it in order to consolidate a new social liberalism.
\end{abstract}

Key words: United States Status. Early constitutionalism. President. Political Rhetoric. Clinton.

\section{INTRODUCCIÓN}

Aun desde la perspectiva desapasionada de un analista foráneo — como lo es el autor de este artículo- resultaría del todo imposible comprender la retórica política que genera la ideología norteamericana (un conjunto plural de 


\section{José J. Sanmartín}

distintas corrientes filosóficas y económicas), si se omitiera un análisis acerca del origen constitutivo de su sistema constitucional y político. Quizá sea Estados Unidos el país occidental más dependiente de su tradición fundacional, hecho particularmente constatable en su retórica política. Al analizar la formación de los Founding Fathers, McClelland subraya que entre sus lecturas aparecían obras de Tácito, Catón, Livio, Salustio, Plutarco. Y ello con el objeto de obtener "detailed accounts of the corruption in Roman politics” (2000:50). Junto a otros autores, como Bolingbroke, Locke o Hume, también los clásicos aportaron contenidos a la institución presidenciaria.

La Historia — y la Ética, como extensión de la misma - fue, por tanto, la base sobre la que se asentaba el edificio institucional a erigir por parte de esos Founding Fathers de la nueva nación. Los discursos de la época demuestran la profunda división respecto a la configuración que hubiera de adoptarse. Conviene tener presente que los Estados Unidos se constituyeron mediante la Declaración de Independencia, pero su ley básica fue la denominada "Articles of Confederation" de 1777, donde no se declaraba la naturaleza del régimen (monárquico o republicano), entre otras ausencias significativas. Es sólo a partir de la aprobación de la Constitución cuando se produce la efectiva definición constitucional. Hamilton - ya en los números 69 y 78 del Federalist - realizó un estudio comparativo sobre las diferencias entre el Presidente de Estados Unidos y el Rey en Inglaterra. Respecto a la labor de los Founding Fathers, por su parte Bryce sostuvo la huella de la tradición monárquica británica. ${ }^{1}$

La norteamericana fue, hasta entonces, la más importante revolución política diseñada y dirigida por un grupo de ideólogos burgueses, en el marco de un territorio poblado masivamente por pequeños propietarios agrícolas y empleados urbanos, cuya máxima inquietud era su situación material. La minoría intelectual que dirige la revuelta contra el gobierno de Su Majestad tuvo que afrontar el hecho de la despolitización de relevantes segmentos sociales, hecho documentado en los trabajos de Knollenberg (2003:201-202), tras sus largas investigaciones históricas en archivos y fuentes directas.

\section{¿REVOLUCIÓN VERSUS INTELIGENCIA?}

El carácter intelectual de la mayoría de los dirigentes revolucionarios fue un rasgo de grueso calado en los parámetros operativos por los que

\footnotetext{
${ }^{1}$ James Bryce. The American Commonwealth. Indianapolis: Liberty Fund, 1995, volumen I, 35. El autor ha preferido conservar el original de las principales expresiones y citas relacionadas con el tema que trata.
} 
Ideas políticas y retóricas del presidencialismo constituyente en EE.UU.

discurrió este proceso de transformación integral, sin parangón en la época moderna. En primer lugar, la rápida politización de la causa separatista activó una espiral que, incluso, escapó al control de sus propios promotores: la anglofobia (en el sentido de aversión radical a las instituciones y costumbres políticas consideradas típicamente británicas) fue asumida como un dogma ideológico por parte de masas populares que, significativa y paradójicamente, creían cumplir, así, el mandato de sus elites, las que quedaban limitadas a un estrecho margen de maniobra a la hora de incorporar cambios más posibilistas. Esa naturaleza rígida de la primera cultura popular verdaderamente nacional proveyó el fermento para la consiguiente religión política generada por principios y productora de dogmas.

De alguna manera, a los líderes revolucionarios como Hamilton o Adams, conscientes de las deficiencias del nuevo sistema político (y preparados para acometer los cambios requeridos), la socialización nacionalista e ideológica realizada desde los púlpitos y tribunas, con la colaboración de la prensa políticamente hiperactiva, contribuyó a la eclosión de un movimiento social identitario nucleado alrededor del culto totémico a la figura presidencial, institución elevada a categoría cuasi intocable de dogma patriótico, pero sometido el Presidente a la crítica de no alcanzar la necesaria romanidad para desempeñar sus altas funciones. La calidad de las referencias históricas que inspiraban el movimiento emancipador impuso un grado de autoexigencia —en verdad insólito — a las elites y a los principios rectores del nuevo régimen constitucional. Sin embargo, y al mismo tiempo, el nivel de rigidez también fue un resultado colateral que afectó al propio funcionamiento del sistema político. La compleja red de "checks and balances” dejó su huella positiva en cuanto a las seguridades que rodeaban al desarrollo institucional; pero, también, marcaba las limitaciones del mismo. Básicamente, como expresara John Adams en 1790, se trataba de controlar los excesos y evitar los abusos (1973:247).

En ese caso, ¿Dónde está el punto de equilibrio? ¿Dónde se halla ese espacio de transición, mutuamente aceptable, entre lo ideal y lo posible? Para el propio Adams, la solución institucional adecuada pasaba por asumir los mejores elementos que aportaba la monarquía, revistiéndolos con la indumentaria más abierta de un sistema representativo de fuertes bases morales en la aplicación de su política. El apetito humano propende hacia el poder y la riqueza, siendo el egoísmo su manifestación más infamante. En este contexto, Adams consideraba indiscutible el deber de ejemplaridad que una minoría ilustrada debe ejercer para orientar hacia el buen camino a la mayoría social que integra al pueblo soberano (1973:246).

Sin embargo, esa clase dirigente debía estar igualmente cortada por el patrón de la ética al servicio de la comunidad. A diferencia de la 


\section{José J. Sanmartín}

indiscriminada jerarquía establecida por la monarquía, la joven República norteamericana debía fundarse en unos sólidos cimientos morales, de tal manera que únicamente los más preparados y honrados ciudadanos pudiesen acceder a la primera magistratura del Estado. De hecho, el prestigio del sistema de gobierno monárquico era, incluso, asumido como una realidad fáctica en los propios debates constituyentes (Kurland y Lerner, 2000:496).

Al mismo tiempo, las exigencias morales — derivadas de una situación excepcional de guerra y urgencia- que se demandaban a la primera magistratura del país obedecieron a una necesidad perentoria de proveer soluciones rápidas y contundentes en un contexto de necesidad absoluta. La presidencia surge en una coyuntura insólitamente violenta, en plena guerra anglonorteamericana, como una respuesta híbrida que satisfaga tanto a conservadores como a liberales de las oligarquías coloniales que apoyan la insurrección militar, no necesariamente la revolución política o, todavía menos, la social. La figura del poder ejecutivo debía convertirse, de facto, en un lugar de encuentro entre diversas posiciones, de tal manera que tanto los monárquicos en rebelión contra la madre patria como los conspicuos republicanos tuviesen un referente común. Los debates constituyentes demuestran claramente que el camino hacia la República no era un tránsito irreversible para los rebeldes, ni que la independencia política significase inevitablemente la ruptura con la institución monárquica. Tengamos presente que la norma anterior, los Articles of Confederation, nunca definió a las treces colonias como una República, ni se dotó de un presidente efectivo para dirigir la acción gubernamental. ${ }^{2}$ De hecho, durante la etapa bélica con Gran Bretaña, sólo de manera harto complicada puede definirse como Gobierno nacional a los mecanismos de concertación que las colonias habían establecido entre sí, básicamente en torno a la estructura y suministros militares. Incluso, en las postrimerías de la guerra de la Independencia, cuando las armas norteamericanas avanzan con éxito, tampoco entonces existe unanimidad respecto al régimen institucional que debería tener el nuevo país.

Sin embargo, el aparente debate sobre monarquía o República se manifestó de manera harto sutil, en referencia generalmente a la distribución de poderes entre el ejecutivo y el legislativo. La consolidación del dominio británico en Canadá así como el temor a una reconquista por parte de la antigua metrópoli impulsaron decisivamente la posición de los republicanos que,

\footnotetext{
${ }^{2}$ Lo que es más, la mención al Presidente que se hace en los Articles of Confederation se refieren a la propia función institucional de la persona encargada de solemnizar las sesiones de los distintos representantes, es decir, se trata de una figura más asamblearia que ejecutiva, muy lejos del Presidente que aparece luego en la Constitución.
} 
Ideas políticas y retóricas del presidencialismo constituyente en EE.UU.

aun así, tuvieron que realizar concesiones en aras de la necesaria unidad nacional. El primer resultado, y el más visible, de ese acuerdo fue la configuración de una institución presidencial que, en realidad, constituía una Corona electiva y revocable, donde un Rey cívico y patriótico dirigiría los destinos del Gobierno. La Presidencia tuvo, desde su origen, el cometido de socializar los nuevos valores políticos de un país emergente, además de convertirse en un espacio de intersección entre diferentes culturas ideológicas. Una institución híbrida donde las hubiere. La Presidencia era un órgano monárquico en un sistema político republicano pero, de tal manera, que resultase posible la reversión institucional si en un momento dado concurriesen las circunstancias para ello. Así, las partes lograron alcanzar un principio de acuerdo - transmutado en un pacto de caballeros- que facilitó la convivencia alrededor de una cultura política nacionalista que no tardó en solemnizar a la propia institución presidencial, prácticamente convertida en el vértice simbólico, y ejecutivo, del poder político.

\section{UN REY PATRIOTA}

Sin embargo, y de acuerdo con los parámetros culturales de los Founding Fathers, la Filosofía era la madre del conocimiento que se expresaba a través de la oratoria. De ahí la importancia conferida —en el debate constituyente - respecto a las atribuciones al nuevo jefe del poder ejecutivo. La Filosofía era un argumento igualmente práctico y válido en el debate político, de una manera natural. En su famoso discurso dedicado a la ratificación del Estado de Nueva York de la Convención sobre la distribución de poderes, el mismo Hamilton podía espetar a su auditorio con razonamientos vocacionalmente filosóficos (2001:503).

Hamilton, Adams, Madison o Jefferson leyeron, entre otros, a Bolingbroke y a los clásicos grecolatinos. En particular, The Idea of a Patriot King - tan del agrado del Presidente John Adams- significaba una "much neglected repudiation of Machiavelli's The Prince, in defense of political morality and limited constitucional government" (McClelland, 2000:143). Efectivamente, el sentido de la política como actividad intrínsecamente ética obedece al deseo primario de los Founding Fathers de apartar para siempre el peligro de la opresión. De ahí que la retórica presidencial también se imbuyese de ese sentido moral conferido a la libertad política (Shogan, 2006).

El maquiavelismo era una carga demasiado gravosa para usarla como cimiento de la arquitectura institucional, al menos oficialmente. Fuentes de legitimidad más inocuas - y útiles - se buscaron entre los clásicos. Tácito, Plutarco y otros aportaron las lecciones morales sobre la inevitable degeneración que provoca el abuso de poder y el envanecimiento personal. De 


\section{José J. Sanmartín}

los pensadores clásicos —incluido Quintiliano- también se administraron los recursos propios de la dialéctica tales como metonimia, sinédocque, epifonema, metáfora, ironía o alegoría. Así, el primer magistrado de la joven República aparecía como un héroe cívico, volcado al servicio público, campeón de los deberes - y garantizador de los derechos - emanados de la Constitución.

El Presidente, ese nuevo Rey Patriota, adquiere en la Constitución un perfil vocacionalmente integrador de las dos corrientes ideológicas predominantes. La garantía para las partes de que esta figura totémica mantendría su neutralidad se basaba en el imperativo categórico de exigirle el cumplimiento inexcusable de un catálogo ético. La ejemplaridad y la solemnidad de sus actos son caras de una misma moneda, inspirada en las instituciones romanas. El vicio, verdadera obsesión entre los constituyentes, ${ }^{3}$ debía ser erradicado de la política, pues aquél había sido la causa primera de la guerra con Inglaterra. La moral debía ser el bálsamo que curaría todas las heridas de los conflictos políticos. En su buena lógica, Adams se manifestó contrario al maquiavelismo como corriente de pensamiento, siquiera asimilable para la democracia estadounidense (1973:245). La vocación formalmente moralizadora de la nueva sociedad buscaba una fuente de legitimidad que proveyese de recursos e ideas para dotar de contenidos efectivos a una religión política, erigida ahora como esperanza común (1973:244). Al mismo tiempo, el orden constitucional también se erigía en garantía formal para los ciudadanos, en tanto la libertad política era el vector compartido con la formulación doctrinal y el ejercicio material de la democracia (Warren, 1992:294).

La importancia de que el discurso presidencial sea claro y preciso ya fue un hecho retórico de grueso calado entre los primeros presidentes. Washington se ajustó -mayormente, aun con salvedades- a un patrón de conducta institucional que le convertía en "rey electo". Sus intervenciones públicas fueron, por lo general, comedidas, atentas a problemas concretos que necesitaban de una solución rápida y efectiva. Pocas y escogidas palabras eran el sello del primer Presidente ante un cuerpo político donde el poder se ponderaba tanto a través de los gestos como de los discursos. La impronta

\footnotetext{
${ }^{3}$ El propio Morris, en las sesiones de la Federal Convention, al debatir sobre la institución presidencial, podía afirmar que "the vice here would not, as in some other parts of the system be curable- It is the most difficult of all rightly to balance the Executive. Make him too weak: The Legislatura will usurp his powers: Make him too strong. He will usurp on the Legislature”, Kurland, Philip B. y Ralph Lerner (editado por). The Founders' Constitution: Volume Three: Article 1, Section 8, Clause 5, through Article 2, Section 1, 2000, 499.
} 
Ideas políticas y retóricas del presidencialismo constituyente en EE.UU.

monárquica tuvo en la presidencia de Washington una acabada realización (Ramsey, 1990:657).

El sentido pragmático de la libertad política gestada en torno a la Constitución —ese prodigioso instrumento al servicio de la oligarquía criolla de las colonias - se conjugó con aspectos particularmente negativos desde la perspectiva formalista de la moral pública británica. La asunción de que la política era un ámbito poco decoroso y, sobre todo, que podían lograrse metas positivas partiendo de móviles incluso perniciosos, constituyó desde su mismo origen parte de la cultura política constituyente “¿Puede el mal servir al bien?”, 4 era tema recurrente entre varios Founding Fathers (Hamilton, 1788). La vanidad del poder, los vicios causados por la ambición política, o la simple erosión moral que producía el ejercicio del gobierno, eran —entre otros- peligros ciertos para la oligarquía revolucionaria. A líderes como Jefferson o Adams les resultaba políticamente necesario demostrar fehacientemente que el recién nacido Estado practicaría la política de manera nítidamente distinta —y mejor — que en la etapa británica.

Cierta pérdida de perspectiva se produjo durante la administración Madison, cuando este Presidente intentó dar un impulso explicativo a su gobierno, de tal manera que la gestualidad institucional de Washington quedó relegada a un segundo plano en favor de un sentimiento de ocupación del espacio retórico. Era preciso estar presente - a través de la palabra- en todos y cada uno de los aspectos donde el Presidente fuera requerido. Madison obvió la sabia lección de Washington respecto a conocer el momento adecuado de guardar silencio y cómo o, lisa y llanamente, a expresar - 0 insinuar, si la ocasión lo requiere- - con gestos lo que la literalidad verbal de lo políticamente correcto no puede hacer. De alguna manera, la presidencia Madison significó, también, cierta pérdida en la interlocución presidencial, en el sentido de limitar ámbitos expresivos de hondo valor político pero de difícil manufactura para un Presidente escasamente dotado en el lenguaje político del simbolismo.

\footnotetext{
${ }^{4}$ Publius (Alexander Hamilton). The Federalist LXXII (publicado bajo el título "Should the President Be Eligible for Reelection?”, Independent Journal, Nueva York, 19 de marzo de 1788). The Debate on the Constitution, Nueva York: The Library of America, 1993, 364. Sobre el posibilismo de los Founding Fathers, el mismo Diamond también constata esta realidad al estudiar la obra de Publius: "if the government is properly arranged, presidents and judges will defend their offices against the legislatura because their pride, love of power or fame, even avarice, will lead them to identify their self-interest with the integrity of their offices”. Martin Diamond. "The Federalist”, en Leo Strauss y Joseph Cropsey (editado por). History of Political Philosophy. Chicago: The University of Chicago Press, 1987, 3a Ed. 672.
} 


\section{José J. Sanmartín}

De ahí que Madison provocase alguna significativa sacudida entre sus contemporáneos a la hora de razonar alguna decisión presidencial. Su ambiguo mensaje del 3 de enero de 1810, en plena guerra napoleónica en Europa, en particular lo referido a determinar "how far further provision may be expedient for putting into actual service, if necessary, any part of the naval armament not now employed", suscitó reacciones enérgicas, generalmente negativas. John Adams recoge el comentario de Crawford para quien el mensaje presidencial fue "so cautiously expressed that every man puts what construction on it he pleases" (1986:127). Un Presidente no puede esparcir sombras de duda sobre su propia toma de decisiones. Las críticas contra Madison arreciaron en los días siguientes, dada la tensión bélica que podía cernirse sobre el país y los peligros implícitos por la falta de tacto en el campo diplomático.

Por otro lado, las contradicciones — aparentes o reales - que aparecen entre los Framers en ocasiones se corresponden con la asunción, o evasión, de responsabilidades inherentes en torno a la función presidencial. Se trataba, lisa y llanamente, de un contexto histórico en ebullición (e improvisación en demasiadas ocasiones) donde la urgencia de los hechos podía imponerse a la serenidad de la reflexión. En semejante contexto, resulta lógica la deriva irresolutiva de la cuestión institucional respecto al ordenamiento político que debía crearse y a la misma definición del nuevo régimen que emergía como un titán de la autonomía burguesa, lejos del doctrinarismo ideológico del Viejo Continente. A ojos de sus impulsores, la norteamericana fue una revolución por la libertad, no por la igualdad. Ésta les parecía una quimera de inasible aprehensión debido a su carácter inmaterial e, incluso, porque resultaba antinatural con el orden de cosas que constituía la misma humanidad. La igualdad plena conduce, inequívocamente, a la tiranía sin resquicios. El pueblo de los Estados Unidos debía dotarse de un sistema político que garantizase la libertad política al tiempo que ésta quedase atemperada por un riguroso sentido de la propiedad, de tal manera que los derechos y deberes estuviesen arraigados a un soporte físico $-\mathrm{y}$ siempre verificable - como eran los medios para ejercerlos. El asumido, y propalado, gusto norteamericano por la posición económica tiene un entronque político en la toma de conciencia - ya por parte de los Founding Fathers - acerca de la necesidad de ejercer los derechos arrebatados a la Corona por la violencia, luego consagrados mediante la Constitución.

\section{UNA REVOLUCIÓN CONSERVADORA}

Ante el riesgo de que la Revolución derivase hacia formas radicales (el temor a la corrupción de las costumbres, el abuso de poder, tan común en los 
Ideas políticas y retóricas del presidencialismo constituyente en EE.UU.

más inspirados Framers en historia romana pero, también, la compartida inquietud de que "su" libertad fuese asaltada por la mayoría social que disponía de menos derechos), o que la libertad de la oligarquía colonial - tan duramente ganada en el campo de batalla - quedase mermada por una extensión democrática sin punto de retorno ni de conclusión, la Convención de Filadelfia adoptó la solución intermedia de instituir una monarquía limitada y constitucional en algunas instituciones que, a su vez, estarían controladas por organismos típicamente republicanos. Esta solución híbrida es la madre de la concepción mixta sobre la Presidencia que, con sus altibajos y evolución, todavía perdura en sus aspectos más sustanciales. En su intervención ante la Federal Convention, también Mason —entre otros constituyentes - ponderó el potencial que aportaba la monarquía como garantía suplementaría para constituir un Gobierno unificado en el nuevo Estado republicano (Kurland y Lerner, 2000:494).

El Presidente se convirtió, así, en un líder sincrético, cuyo imperium dependía - en un proceso de retroalimentación mutua - de su potestas. La búsqueda de gloria, para sí y para su patria, era un deber institucional que el nuevo Rey Patriota estaba obligado a satisfacer ante su pueblo. El tributo al nacionalismo era ineludible en un país recién nacido que, además, confería al poder político la posibilidad de una gradual — y siempre moderada - apertura democrática. Sin embargo, el surco primero de la cultura política que emergía se orientaba en distinta dirección. La exigencia primera de un importante número de ideólogos revolucionarios pasaba por la necesidad de crear un Gobierno fuerte, capaz de afrontar cualquier desafío, dentro o fuera de las fronteras del país. Y ello, por lo general, apoyado en una doctrina vehementemente religiosa, como, por ejemplo, realizara John Smalley en su sermón On the Evils of a Weak Government (1800).

Por su parte, el propio Adams consideró que la monarquía reunía aspectos singularmente valiosos para dotar de estabilidad a un país. De hecho, en su Discourses on Davila (1790) Adams sostuvo la necesidad de recuperar la austeridad como principio cardinal de un republicanismo fundado sobre cimientos monárquicos. Lo que ha destruido la presencia de la Corona británica en las Trece Colonias — afirmaba quien fuera Presidente- ha sido, básicamente, la traición a los ideales de servicio al pueblo que encarnaba la misma Institución. Sin embargo, la concesión de honores, el reconocimiento de méritos, los actos de socialización política, son elementos cohesivos que aportan empaque a una comunidad. Los oropeles fatuos y los fastos altisonantes, así como demás parafernalia, poco o nada pueden enriquecer la vida política de un país.

Si bien es cierto que la Independencia liberó al nuevo país de algunas ataduras de servidumbre, también lo es que éstas nunca fueron en 


\section{José J. Sanmartín}

Norteamérica tan intensas como las existentes —antes y después de 1776en la Europa continental. El papel de la Corona fue taumatúrgico para actuar como dique político frente a semejante problema. Ante una mayor dispersión conceptual europea, la joven nación americana entronizó el pragmatismo como crisol de la identidad compartida. Empirismo, sí, pero también un fuerte componente doctrinal invadió las fuentes originales en las que se basó la nueva República. Ésta, de hecho, no surgió como manifestación destilada de la Ilustración. Al contrario, la inspiración primera para la Revolución de las Trece Colonias tuvo en las Biblias protestantes un apoyo más constante que en las obras de Voltaire o, incluso, de Montesquieu. ${ }^{5}$

La rebelión es contra la supuesta y denostada opresión británica y contra un segmento social autóctono que, en las colonias, se consideraba lesionado por la política fiscal de Londres. El objetivo no era tanto constituir una democracia plena sino, más bien, desarrollar un nuevo sistema político donde se pudiesen decidir los límites de las tasas impositivas y demás disposiciones. Así y todo, la concepción material de lo que debía ser un sistema político permitió una interpretación progresivamente más abierta de los valores constitucionales. Este proceso no debe confundirse con una liberalización —en el sentido político del término-- del régimen presidencialista, de la cual sólo puede hablarse hasta la década de los años treinta del siglo XIX. De hecho, el impulso decisivo hacia la democratización se produjo sólo tras la Guerra Civil.

\section{UN PASADO QUE ES PRESENTE}

Al mismo tiempo, resulta indispensable subrayar la importancia que la Antigüedad tuvo a la hora de inspirar el proceso gradual conformador de Estados Unidos (McClellan, 2000:14-22). Roma —y, también, Atenasdesempeñó un papel casi totémico en la floreciente cultura política que estaba surgiendo en las antiguas Trece Colonias. De esta manera, en The Federalist $\mathrm{N}^{\circ} 70$, incluso Hamilton recurrió al ejemplo (negativo y positivo, los errores a evitar y las virtudes a encarnar) que la densa historia política romana podía

\footnotetext{
${ }^{5}$ El propio Voltaire era demonizado como ateo por no pocos ideólogos de la Revolución, además de ser literalmente acusado de introducir la irreligiosidad en la sociedad de su tiempo. Recordemos las puritanas admoniciones de Dwight en 1798: "Shall we, my brethren, become partakers of these sins? Shall we introduce them into our government, our schools, our familias? Shall our sons become the disciples of Voltaire, and the dragoons of Marat; or our daughters the concubines of the Illuminati?”. Timothy Dwight. "The Duty of Americans, at the Present Crisis", en Ellis Sandoz (editado por). Political Sermons of the American Founding Era, 1730-1805. Indianapolis: Liberty Fund, 1998, 2a Ed. Vol. 2, 1383.
} 
Ideas políticas y retóricas del presidencialismo constituyente en EE.UU.

aportar. El supuesto del consulado romano le era particular-mente aleccionador a la hora de diseñar el gobierno de Estados Unidos. Y la cautela que debía adoptarse (2001:375).

La propuesta hamiltoniana de configurar al nuevo país en torno a un gobierno unificado recibió una aguda oleada de críticas desde diversos sectores, incluidos los púlpitos protestantes. En un vibrante discurso, Wortman advertía de la existencia de un British party en Estados Unidos, contrario a la República y partidario de la instauración monárquica; entre otros, este polémico predicador identificaba a Hamilton y a Adams como miembros de esa corriente (1998:1524).

Sin duda, la acusación de anglofilia era demasiado grave en el cambio del siglo XVII al XIX como para que los norteamericanos ilustrados que deseaban un saneamiento de su sistema político, en sentido parlamentarista, pudieran manifestarse tal cual. Si dos héroes de la Revolución eran vejados públicamente por un influyente orador ultranacionalista, ¿Qué otros agravios debería arrostrar el resto de los correligionarios de Adams y Hamilton? De hecho, el propio Wortman amonestó a Adams - en franca contradicción con la libertad de expresión consagrada en la Constitución que el vitriólico reverendo aseguraba defender - por haber "escrito abiertamente a favor de los principios aristocráticos”. Al desventurado Hamilton —un revolucionario de la primera oleada y prudentemente interesado en conferir mayor estabilidad y representatividad al nuevo sistema político- le cayó el plomizo cargo de "proponer una auténtica Constitución monárquica" (Wortman, 1998:1527). Sin embargo, aunque exageradas, las invectivas de Wortman sí acertaron en un punto: la crítica que formula contra la opacidad informativa de una parte de lo deliberado en la Federal Convention, ¿Qué se oculta tras ello? ¿Por qué ignora el pueblo soberano los pormenores de lo allí discutido? Si a ello se une la creciente moderación de una parte de sus líderes, incluidos varios Founding Fathers, que pasan de un juvenil republicanismo geométrico a otro variable, donde resultaría posible incorporar elementos monárquicos que provean de mayor unidad nacional y de un gobierno realmente efectivo para la República (permanente objetivo de Hamilton, por ejemplo) se comprende, en parte, la reacción visceral de aquellos fundamentalistas cristianos, fanatizados en torno al culto de una nueva República de Savonarola que purificase pecados y redimiese culpas.

En el recién nacido Estado, entre los más enérgicos partidarios del sistema republicano figuran los esencialistas del protestantismo, los evangélicos de la Biblia, los creyentes más intransigentes en materia moral y religiosa; aquellos, en definitiva, que consideran a la República no como un bien político, sino como un instrumento al servicio de su idea de pueblo 


\section{José J. Sanmartín}

cristiano; sin fisuras, ni esquirlas. Para este segmento, la monarquía representaría, inevitablemente, el vicio y la perversión, no sólo en política.

Toda tentativa por parte del liderazgo nacional, incluidos algunos Founding Fathers, de corregir algunos defectos en el funcionamiento del sistema político, fue tachada de traición a los principios cardinales de la Revolución. Hasta la controvertida Mercy Otis Warren escribió en esos términos un artículo en prensa de amplia difusión (1788).

Siempre recelosa de una Constitución que consideraba poderosamente influida por el pensamiento monárquico, Warren se esforzó por defender el republicanismo como base primera para el desarrollo institucional de Estados Unidos. Incluso, una fervorosa partidaria de la República puritana como era ella, comprendió que ese sistema de gobierno no era masivamente seguido por los patriotas que habían culminado la revolución separatista contra Gran Bretaña (Warren, 1989, II:657).

Es una realidad que entre los muchos opositores a la Constitución de 1787 aparecían, también, aquellos partidarios de que los Estados detentasen mayor soberanía frente al Gobierno Federal. Además, el temor implícito en la cultura política emergente manifestaba una desconfianza patológica contra toda supuesta influencia británica en la configuración institucional del país, que incidió en el ocultamiento de las tendencias monárquicas de algunos líderes revolucionarios. ${ }^{6}$ El temor a la acusación de anglofilia exigía prudencia. Y, ello, aun cuando entre los ilustrados Founding Fathers se comprendiesen las insuficiencias de la propia Constitución, donde —entre otros defectos - el carácter parlamentario del sistema político era de menor calado que en Gran Bretaña. James Bryce pudo colegir la actitud contradictoria que, por un lado, impulsaba hacia la regeneración del régimen y, por otro, la bloqueaba. Todo residía en un conjunto de prejuicios alimentados - $-\mathrm{y}$, en algunos casos, surgidos - durante la cruenta guerra contra Inglaterra. El origen bélico de la independencia norteamericana tuvo un impacto decisivo no sólo sobre la estructura institucional resultante sino, también, sobre sus valores ideológicos, que perduraron como parte de una religión política

${ }^{6}$ El mismo Washington requirió silencio a un fervoroso admirador, que le propuso su entronización como monarca del país. El tono fulminante del entonces comandante militar supremo de la causa secesionista parece indicativo de la tensión política del momento, ya en la etapa final de la guerra, cuando era posible esbozar el inmediato futuro de independencia para el nuevo país. "Let me conjure you then, if you have any regard for your Country, concern for yourself or posterity, or respect for me, to banish these thoughts from your Mind, and never comunícate, as from yourself, or any one else, a sentiment of the like Nature”. George Washington. Writings. Nueva York: The Library of America, 1997, 469. Se trata de una carta escrita en Newburgh a Lewis Nicola el 22 de mayo de 1782. 
Ideas políticas y retóricas del presidencialismo constituyente en EE.UU.

particularmente rígida en algunos aspectos. De esta manera, el sistema político no pudo modernizarse de forma más afirmativa en tanto resultara intransitable adoptar el camino de las reformas que el país necesitaba. En definitiva, se generó un ordenamiento institucional único por sus peculiaridades y contradicciones.

La Presidencia fue una concesión pactada que, por sus fuertes connotaciones monárquicas, asumía para sí la responsabilidad —y el deber institucional- de desbloquear las situaciones de crisis. Así y todo, los Framers fueron incapaces de avanzar más en el espacio público pues, como queda explicado, se dieron de bruces con una población soliviantada contra las posibles soluciones de cuño europeo que, desde el principio, se manifestaron necesarias. La desconfianza hacia la figura del Presidente por parte de los críticos a la Constitución ya, entonces, fue especialmente significativa (Bryce, 1995:1535).

\section{PODER POLÍTICO COMO TÓTEM SIMBÓLICO}

La figura totémica de un Presidente atento y despierto, ágil de reflejos, pletórico de energía, cuya principal misión — porque es una labor elevada a la categoría de misión, no sólo de función - consiste en gobernar para el bien general, remite umbilicalmente a la configuración que del Rey Patriota hiciera un político como John Bolingbroke.

Paradójica y significativamente, The Idea of the Patriot King influyó más sobre la incipiente República surgida de la escisión colonial que en la madre patria. El peso de un pensador -británico de pro, moderado conservador y monárquico leal— como Bolingbroke fue clave para la conformación constitucional de la figura del Presidente, una incorporación realizada a posteriori de lograrse la independencia. La concepción de una instancia superior - rey para Bolingbroke; presidente para los constituyentes reunidos en la tercera convención de Filadelfia - que actuase como padre del pueblo, ejerciendo un sentido práctico del Estado elevado sobre las luchas internas de los partidos —única vía de adquirir la credibilidad indispensable para acometer sus tareas ejecutivas y simbólicas - tiene una importante influencia en la cultura política norteamericana, desde el primer momento.

La virtud cívica se convirtió, pues, en basamento ideológico para un renacido patriotismo constitucional, nucleado en torno al auténtico Patriot King que, desde una perspectiva republicana, debería ejercer el Presidente como suma de símbolos y crisol de funciones. El papel fundamental que la ética desempeñaba en el nuevo sistema político obedecía a la necesidad de purificar y pervivir. En primer lugar, eliminar las impurezas (corrupción del gobierno, abuso de poder, etc.) que deslegitimaron, según los Founding 


\section{José J. Sanmartín}

Fathers, la autoridad británica en Norteamérica. Por otro lado, también se trataba de establecer un régimen lo suficientemente exigente en materia de costumbres en la sociedad política —y fiscalización sobre la elite dirigentede tal manera que se pudiera garantizar un futuro despejado, al menos, de la parálisis y desaciertos que se vinculaban al fallido reinado de Jorge III. De hecho, McDonald ha indicado el carácter defectivo de Jorge III como Rey Patriota (1994:122).

Los Founding Fathers crearon un nuevo monarca republicano, como fuerza salvífica —y puritana — que erradicase la corrupción, la iniquidad y los malos hábitos. Un Presidente que debía surgir de la política, pero tenía que aparecer por encima de la política (Public Papers of the Presidents of the United States, 1997:109). El Presidente se erige, así, en la encarnación del poder y símbolo de la nación. A este carácter dual debe añadirse otro, igualmente importante, a lo largo del siglo XIX: el representante del pueblo. Desde esta triple perspectiva, es absolutamente complejo, como podemos desentrañar, el poder de la República desde su pináculo. Las acusaciones contra el Presidente Adams de ser un monárquico latente no eran tan insólitas —ni tan infundadas - en la América de finales del siglo XVIII y principios del XIX. La reformulación republicana hecha — sobre todo por Jefferson- de la teoría de Bolingbroke dejó un poso de monarquismo en la figura presidencial.

La huella monárquica sobre varias —e, incluso, distintas- instituciones, tradiciones y costumbres políticas de Estados Unidos es todavía visible. Y lo fue más, si cabe, en la extensa etapa constituyente, donde el poder del pueblo buscaba anhelante una nueva configuración (Los símbolos de la res publica; la República de los símbolos). Como toda sociedad conservadora de su pasado hipostasiado, orgullosa de su Historia nacional, Estados Unidos afirma — al tiempo que reivindica, hasta exige — la protección de la Divina Providencia como elemento consustancial a su identidad política. Las apelaciones a Dios son indispensables en el discurso moral en que un Presidente debe insertarse. La libertad política que debe propalar un "Rey Patriota" depende, pues, de la ejemplaridad que destile en su ejecutoria personal e institucional. El Presidente es un icono simbólico donde el país político se mira. La más mínima mácula sobre el uniforme institucional de la jefatura del Estado contaminaría nocivamente al resto de la sociedad.

Si bien la preparación cultural de Jefferson era superior a la de Washington, también es cierto que éste redactaba de una manera funcional y directa, con frases breves y uso continuado de abreviaciones. El líder militar prefería aludir - y apoyarse- en la experiencia, aún cuando no descartase formular apelaciones a la Historia, aunque prefería aludir a la experiencia. Por el contrario, su antagonista $-y$ luego tercer Presidente- exhibió el dominio 
Ideas políticas y retóricas del presidencialismo constituyente en EE.UU.

de su vasta cultura histórica y política, además de un refinamiento en su oratoria de inspiración clásica. Jefferson, junto a Hamilton, fue el líder revolucionario de mayor influencia intelectual. Además de redactar la Declaración de Independencia, también dejó su impronta sobre la Constitución y sobre la figura presidencial. La retórica debía desempeñar un lugar encomiable en el sistema político como lugar de encuentro entre el poder y el pueblo que investía a sus autoridades. Proposición e invocación: la nueva Roma había nacido.

De ahí que Jefferson tratase de movilizar a su favor el ánimo de los oyentes. No se trataba, pues, únicamente de exponer hechos sino, también, de socializar ideas políticas. Desde la perspectiva jeffersoniana, el Presidente ejercía como imponente "Rey Patriota” quien, además de ser un buen orador - conforme a la visión de Bolingbroke - también debía ofrecer esa grandeza moral que Demóstenes exigió a su tiempo. La elección de un Presidente era no sólo materia de pura racionalidad sino, también, ámbito abierto a las emociones (Bryce, 1995:73).

En su momento, el carácter plebiscitario que quiso imprimir a la Presidencia adquirió en Lincoln un impulso decisivo. Al socaire de los poderes de guerra, el entonces Presidente claramente se extralimitó en sus funciones, apelando para ello a los deberes del momento y a la naturaleza electiva de su cargo. La democracia como autojustificación a la invasión de poderes. En plena Guerra Civil, cuando la violencia y el desenfreno eran elementos comunes de la vida colectiva, Lincoln realizó unas reflexiones en público donde reconocía el creciente papel que el providencialismo estaba desempeñando en sus decisiones. Sin embargo, ya encarrilada la fase final de la guerra, el Presidente podía manifestarse más sincero en su correspondencia privada (Lincoln, 1989:529-530-585).

La rigidez formalista respecto al funcionamiento del sistema político norteamericano que aplicó Lincoln en algunas situaciones, paradójicamente fue conculcada cuando la necesidad se impuso a la legalidad. De manera significativa, el Presidente —abogado de profesión- que ganó en el campo de batalla, no logró otro tanto en el terreno de la ley. Lincoln impuso sus criterios contra viento y marea, fueran éstos militares o civiles, y para ello se valió de sus prodigiosas cualidades oratorias. Los discursos de este Presidente podían galvanizar a multitudes dispersas y lejanas pues la retórica que empleaba se basaba en la impresión más que en la literalidad. Frases cortas, con calculadas y sencillas metáforas que "hacían ver"; palabras que, inevitablemente, serían más oídas que leídas, más repetidas que escuchadas. Lincoln era consciente de que actuaba en una sociedad que vivía casi segmentada entre territorios distintos donde las noticias llegaban de manera irregular y tardíamente; que apenas disponía de una prensa que pudiera 


\section{José J. Sanmartín}

llamarse de ámbito nacional; en definitiva, un universo político todavía pendiente de su plena socialización ideológica, donde las particularidades podían ser más relevantes que la troncalidad compartida en materia de cultura política.

Esta situación fue exponencialmente aumentada con motivo de la Guerra Civil. La conflagración bélica entre el Gobierno Federal y los Estados Confederados de América desarrolló un conflicto, también, en el campo de la retórica política. Los discursos más elaborados y densos de Jefferson Davis apelaban a una racionalidad jurídica, con una propensión genuina hacia el argumentario legitimador basado en los principios rectores de los Founding Fathers; en definitiva, la idea de la refundación de una nueva patria, continuadora auténtica de la gloriosa tradición nacional surgida en 1776. El Presidente del Gobierno de los Estados Confederados de América podía postularse como un heredero de Jefferson e, incluso, de Washington, a quienes pretendía suceder. Ya en su etapa anterior a la guerra, debido a su sólida carrera política, Davis se señaló como un líder sureño que disponía de un mensaje definido y de un envoltorio atractivo, capaz de llegar a auditorios aparentemente lejanos (1990, I:483). Ese grado de idealismo empírico y patriotismo civil constituía un atributo primigenio de un escogido grupo de políticos, destinados a desempeñar las máximas responsabilidades del país. Davis, por derecho propio, fue considerado el candidato adecuado para ocupar la presidencia del naciente gobierno confederado en 1861 (1990, I:200).

\section{LA RETÓRICA COMO ARTE DE LO POSIBLE}

Claramente, en Estados Unidos la retórica política del "establishment” institucional ha utilizado los recursos clásicos; entre otros, los procedentes de Demóstenes. Con mayor sentido práctico que Platón, Demóstenes argumentó sobre la identificación del bien y la necesidad de ir en pos suyo. El convencimiento sólo empieza en uno mismo; si el orador no cree en sus palabras, difícilmente las hará creer. En su momento, Clinton, como antes Lincoln o Kennedy, recurrió a una imagen ya estandarizada del Presidente en ejercicio de su majestas: frases cortas, entonación firme, gesto seguro, buena pronunciación, correcta vocalización.

Ya en pleno siglo XIX, una presencia intelectual de escasa influencia en la Filosofía tradicional norteamericana, pero de mayor ascendencia en materia de retórica política, fue la obra de Arthur Schopenhauer quien elaboró un estudio sobre la capacidad de convencimiento, para las personas, contra los argumentos. Las treinta y ocho estratagemas que reunió constituían un elenco recopilatorio de las mejores bazas a emplear por un rétor. Sea a favor o en contra, Schopenhauer explicaba los mecanismos internos para destruir la 
Ideas políticas y retóricas del presidencialismo constituyente en EE.UU.

argumentación contraria y, lógicamente, reafirmar las propias. Durante su etapa formativa en Inglaterra, como becario del Programa Rhodes destinado en la Universidad de Oxford, el joven estudiante Clinton tuvo su primer contacto intelectual con las estratagemas de Schopenhauer. La relación didáctica que se establece entre el pensamiento del filósofo alemán y la ejecutoria del líder universitario sólo puede calificarse de fructífera, dada la singular aplicación que hace Clinton de las ideas y conceptos de Schopenhauer. ${ }^{7}$ El trasvase de ese cuerpo doctrinal, debidamente depurado de rigideces escolásticas e impurezas analíticas, conformará parte de la base sobre la que asienta su retórica política.

El sentido del marketing político practicado por Clinton está claramente imbuido por el concepto de apagose que pergeñase Schopenhauer. ${ }^{8}$ Éste consideraba que la reversio argumenti se definía como la situación donde "un argumento, que el adversario quiere utilizar a su favor, puede con más razón ser utilizado en su contra” (2000:49). El Presidente Clinton fue un maestro en el manejo de la reversio argumenti. De hecho, se esforzó siempre por desentrañar el argumento contrario al objeto, no tanto de destruirlo formalmente, sino de integrarlo en su propia posición. Y ésta es una diferencia esencial con Schopenhauer: Clinton siempre rechazó el ejercicio de las técnicas retóricas más beligerantes, aquéllas que van destinadas no sólo a aniquilar el argumentario sino, también, a desacreditar a su exponente. ${ }^{9}$ Las

\footnotetext{
${ }^{7}$ El conocimiento de Clinton de la obra del pensador alemán procede de su etapa universitaria, tanto en Georgetown como en Oxford. Bajo el título de Eristiche Dialektik oder die Kunts, Recht zu behalten, in 38 Kunstgriffen alargestellt (Dialéctica erística o el arte de tener razón expuesto en 38 estratagemas), este tratado sólo pudo publicarse en 1864, cuatro años después del fallecimiento de su autor en una obra general Aus Schopenhauer's handschriftlichen Nachlass (Del legado manuscrito de Schopenhauer). A pesar de las pocas - aunque muy diferentes- ediciones en lengua alemana que se han publicado de esta obra, citaremos aquí por la versión castellana traducida por Dionisio Garzón (El arte de tener razón expuesto en 38 estratagemas. Dialéctica erística. Madrid: Edaf, 2000) que se basa en la rigurosa edición de Arthur Hübscher contenida en el volumen tercero de Arthur Schopenhauer. Der handschriftliche Nachlass. Frankfurt del Meno: Waldemar Kramer, 1966-1975, cinco Vols.

${ }^{8}$ Esta figura retórica se basa en la asunción de "la tesis del adversario como verdadera y después demostramos la consecuencia que se sigue si, combinándola con cualquier otra proposición aceptada como verdadera, la adoptamos como premisa para un silogismo del cual se deduce una conclusión obviamente falsa”. Arthur Schopenhauer. El arte de tener razón expuesto en 38 estratagemas. Dialéctica erística (2000:29).

${ }^{9}$ De los recursos retóricos suministrados por Schopenhauer (entre otros, el "argumentum ad rem", el "argumentum ad hominem", el "argumentum ad auditors", el "argumentum ad verecundiam", o la "ultima ratio stultorum") algunos implementados por Clinton de manera harto personal y limitada, otros apenas fueron utilizados como el denominado "último refugio de los necios”, demasiado ofensivo para un político que debía persuadir para ganar al
} 


\section{José J. Sanmartín}

buenas formas son esenciales y Clinton - a diferencia del filósofo de hosco carácter - vive políticamente de una clientela que tiene nombre propio: el pueblo de los Estados Unidos. Este vínculo inextricable entre primer mandatario y soberanía popular hace del Presidente un nuevo intérprete de la tradición finisecular iniciada en los Founding Fathers. En momentos de crisis (el proceso de impeachment, por ejemplo) Clinton sublimó su presencia mediática personal hasta alcanzar la categoría de continuador de la llama sagrada constituida por la American democracy.

Martin Diamond sostiene la existencia de una crucial assumption sobre la formulación de los poderes en la recién nacida República (1987:672) sustentada en la idea de una elite al servicio de la comunidad. Un grupo de dirigentes que pretende la mejora de una sociedad, asumiendo su status social como una responsabilidad, no como un privilegio (Wills, 1994:155).

Por lo mismo, al dirigirse al país, el Presidente está obligado a trascender sus propios límites y convenciones, de manera que, además de aparecer como un límpido espejo donde la virtud cívica resplandezca en todo su esplendor, también le resulta necesario ofrecer una imagen de impecable neutralidad. El líder lo es de todos y para todos, y sus decisiones se adoptan para servir ese bien común que llamamos democracia. Según Wills, Washington creó un lenguaje de "tacto y protocolo" que sacralizó la función presidencial en el marco de una nueva liturgia política. El poder de la palabra constituyó, desde su origen, alimento primero para la institución presidencial (1994:154-219).

Esa herencia — como formulación teórica y aplicación práctica- - tuvo en la Presidencia una consumada plasmación, de la cual Clinton ha sido hábil continuador. La primera magistratura del país debe aportar al país político un espacio donde puedan converger - $\mathrm{y}$, deseablemente, también reconciliarsedistintas ideas políticas que pueblan el universo ideológico del pueblo estadounidense. Una vez allí, un Presidente experto en Retórica debería ser capaz de entregar a la comunidad principios morales en vez de ideas políticas; la socialización del idealismo fue la base de la acción retórica de Clinton, que moldeaba las palabras y administraba los tiempos. La influencia del universo valorativo que conformaron los Founding Fathers de los Estados Unidos dejó su impronta en la Presidencia como una institución simbólica que encarna, desde entonces, un empirismo - mayormente maquiavélico, aunque nunca reconocido - atemperado por un idealismo formal pero sólo parcialmente efectivo. Esa tradición cultural $-\mathrm{y}$ sus contradicciones- llega hasta el

interlocutor, no humillar para derrotar al enemigo. El arte de tener razón convenciendo a los demás de ello. 
Ideas políticas y retóricas del presidencialismo constituyente en EE.UU.

tiempo presente, donde un Presidente como Clinton recuperó la vieja bandera del American Dream, actualizándolo con el objeto de consolidar un nuevo liberalismo social. El pasado y el presente como síntesis de una épica nacional proyectada hacia el futuro. La inspiración monárquica de la primera magistratura del Estado queda así expuesta, una vez más, en los contenidos efectivos que tiene, al tiempo que la propia evolución de la institución presidencial confirma esta vocación.

El Presidente ejerce como un mecanismo de control suplementario. Más allá, incluso, de las funciones establecidas en la Constitución, el Presidente se erige como la última reserva institucional del sistema político. Las crisis gubernamentales pero, también, los escándalos personales, afectan profundamente a la Casa Blanca, en tanto los Framers no fueron capaces de separar adecuadamente entre las funciones simbólica y ejecutiva que distingue a todo gobierno representativo (Rakove, 2004:19).

\author{
Universidad de Alicante* \\ Facultad de Derecho \\ Departamento de Estudios Jurídicos del Estado \\ Apartado 99- 03080 Alicante (España) \\ jose.sanmartin@ua.es
}

\title{
BIBLIOGRAFÍA
}

ADAMS, Henry. History of the United States of America during the Administrations of James Madison, 1809-1817. Nueva York: The Library of America, 1986.

ADAMS, John. Discourses on Davila. Nueva York: Da Capo Press, 1973.

BOLINGBROKE, John (Vizconde de). The Idea of a Patriot King, en http://socserv.mcmaster.ca/econ/ugcm/3ll3/bolingbroke/king.html; fecha de descarga: 8 de agosto de 2008).

BRYCE, James. The American Commonwealth. Indianapolis: Liberty Fund, volumen I, 1995.

DAVIS, Jefferson. The Rise and Fall of the Confederate Government. Nueva York: Da Capo Press, volumen I, 1990.

DIAMOND, Martin. "The Federalist", en Leo STRAUSS and Joseph CROPSEY (editado por). History of Political Philosophy. Chicago: The University of Chicago Press, 1987.

HAMILTON, Alexander. Writings. Nueva York: The Library of America, 2001.

KNOLLENBERG, Bernhard. Growth of the American Revolution: 17661775. Indianapolis: Liberty Fund, 2003. 
José J. Sanmartín

KURLAND, Philip B. y Ralph LERNER (editado por). The Founders' Constitution: Volume Three: Article 1, Section 8, Clause 5, through Article 2, Section 1. Indianapolis: Liberty Fund, 2000.

LINCOLN, Abraham. Speeches and Writings, 1859-1865: Speeches, Letters, and Miscellaneous Writings: Presidencial Messages and Proclamations. Nueva York: The Library of America, 1989.

MCDONALD, Forrest. The American Presidency: An Intellectual History. Lawrence: University Press of Kansas, 1994.

MCCLELLAN, James. Liberty, Order and Justice. An Introduction to the Constitucional Principles of American Government. Indianapolis: Liberty Fund, 2000.

PUBLIUS (Alexander HAMILTON). The Federalist LXXII (publicado bajo el título "Should the President Be Eligible for Reelection", Independent Journal, Nueva York, 19 de marzo de 1788). The Debate on the Constitution. Nueva York: The Library of America, 1993.

RAKOVE, Jack N. "From the Old Congress to the New", en Julian E. Zelizer (editor). The American Congress: The Building of Democracy. Boston: Houghton Mifflin Company, 2004.

RAMSEY, David. The History of the American Revolution. Indianapolis, Liberty Fund, volumen II, 1990.

SCHOPENHAUER, Arthur. El arte de tener razón expuesto en 38 estratagemas. Dialéctica erística. Madrid: Edaf, 2000.

SHOGAN, Colleen J. The Moral Rhetoric of American Presidents. College Station: Texas A \& M University Press, 2006.

SMALLEY, John. Sermon Preached on the General Election at Hartford, in Connecticut, May 8, 1800. Hartford: Hudson and Goodwin, 1800.

WASHINGTON, George. Writings. Nueva York: The Library of America, 1997.

WARREN, Mercy (OTIS). History of the Rise, Progress and Termination of the American Revolution. Indianapolis: Liberty Fund, volumen II, 1989.

WILLS, Garry. Certain Trumpets. The Call of Leaders. Nueva York: Simon \& Schuster, 1994.

WORTMAN, Tunis. "A Solemn Address to Christians and Patriots upon the Approaching Election of a President of the United States" (1800), en Ellis Sandoz (editado por). Political Sermons of the American Founding Era, 1730-1805. Indianapolis: Liberty Fund, 1998, volumen II. La publicación original de este discurso fue realizada por David Denniston. Nueva York, 1800. 